\title{
Towards the Enactment of Learning Situations Connecting Formal and Non-Formal Learning in SLEs
}

\author{
Sergio Serrano-Iglesias, Miguel L. Bote-Lorenzo, Eduardo Gómez-Sánchez, \\ Juan I. Asensio-Pérez, and Guillermo Vega-Gorgojo \\ GSIC/EMIC Research Group, Universidad de Valladolid, Spain \\ sergio@gsic.uva.es \\ \{migbot, edugom, juaase, guiveg\} @tel.uva.es
}

\begin{abstract}
Smart Learning Environments hold promise of adapting learning processes to the individual context of students and connecting formal with nonformal learning. To do so, SLEs need to know the current context of the students, regardless of the physical or virtual space where learning takes place. This paper presents an architecture that assists in the deployment and enactment of learning situations across-spaces, able to sense and react to changes in the students' context in order to adapt the learning process.
\end{abstract}

Keywords: smart learning environments, context, formal and non-formal learning, reaction, enactment

\section{Introduction}

Smart Learning Environments (SLEs) are Technology-Enhanced Learning (TEL) environments able to adapt the students' learning experience and to provide them with personalized support at the right time and place, considering their individual needs and context [1]. SLEs can support across spaces learning situations (i.e. situations spanning multiple virtual and physical spaces [2]) and involving different technological elements such as Virtual Learning Environments (VLEs), mobile and wearable devices or Internet of Things (IoT) devices. All these components of SLEs provide data about students' actions and progress, which can be used for making adaptation decisions at enactment time.

The inherent support of SLEs to adaptable across-spaces learning provides interesting opportunities for connecting formal and non-formal learning [3]. To do so, SLEs need to evaluate the context of each student, comprising what happens in multiple spaces (e.g. posts, reads, quizzes, etc. in the VLE; or movements, actions and interactions with others sensed by IoT in the physical space), detect opportunities to enrich the learning process in non-formal contexts by proposing additional resources and activities that connect to what is formally designed to be 
Serrano-Iglesias S., Bote-Lorenzo M.L., Gómez-Sánchez E., Asensio-Pérez J.I., Vega-Gorgojo G. (2019) Towards the Enactment of Learning Situations Connecting Formal and Non-Formal Learning in SLEs. In: Chang M. et al. (eds) Foundations and Trends in Smart Learning. Lecture Notes in Educational Technology. Springer, Singapore (C) 2019 Springer Nature Switzerland AG. Part of Springer Nature. The final authenticated version is available online at https://doi.org/10.1007/978-981-13-6908-7_27

learned, and finally intervene at the right time and place suggesting these extra learning resources.

To the best of our knowledge, there are no previous works in the literature that address the problem of combining the support to formal and non-formal learning happening across-spaces within the context of SLEs. This paper proposes an SLE architecture that deals with this open issue.

\section{$2 \quad$ Architecture Proposal}

SLEs can be characterized by the following actions at enactment time: (1) sense the students' actions and their current context, (2) analyze the gathered data to identify their individual context and (3) react accordingly and offer the adapted learning resources and activities. All these actions may happen in any of the different learning spaces in which students formally participate, but also outside them, extending the support to non-formal settings. Nevertheless, to the best of our knowledge, the SLEs proposals in the literature focus on only one of these spaces.

The interest in connecting different learning spaces is not a novelty within the TEL community. Notably, GLUEPS-AR [4] is a system that can take a formalized learning design and set up the tools, resources and groups of students to carry it out across multiple spaces, including VLEs, 3D Virtual Globes and Augmented Reality browsers, allowing students to access the same artifacts in all of them, thanks to an adaptor-based architecture that favors software reuse and third-party tool integration. Nevertheless, GLUEPS-AR cannot be considered a SLE since it cannot sense students' actions, analyze the context or intervene during run time. Besides, it provides no connection between formal and non-formal learning since all learning activities need to be designed by the teacher a priori.

This paper proposes the addition of modules to GLUEPS-AR to enable these features, as shown in Figure 1. More specifically, new modules include: (1) the inclusion of IoT devices, which enhance the interactions with the physical space; (2) the Context Identifier and MultiModal Learning Analytics (MMLA) modules, that benefit from the diversity of complementary data sources from different learning spaces for a better understanding of both students' individual contexts and the learning processes [5]; and (3) the Reaction Module, which determines the appropriate way to assist each student based on the results of the previous modules.

With the new additions, the system will be able to assist students across-spaces while connecting formal and non-formal learning. Once the instructor has produced a learning situation, enriched with metadata about its educational context, the system configures and deploys the required resources thanks to the adaptors to the spaces in which students are expected to participate. At enactment time, the monitoring modules present in these adaptors sense students' interactions with 
resources existing in these spaces and send the data to both the Context Identifier and MMLA modules. The results of these modules are then used by the Reaction Module to take decisions to intervene in the students' current context, once again via the adaptors without the intervention of teachers.

Fig. 1. Architecture proposal, based on GLUEPS-ER [4]. The original architecture

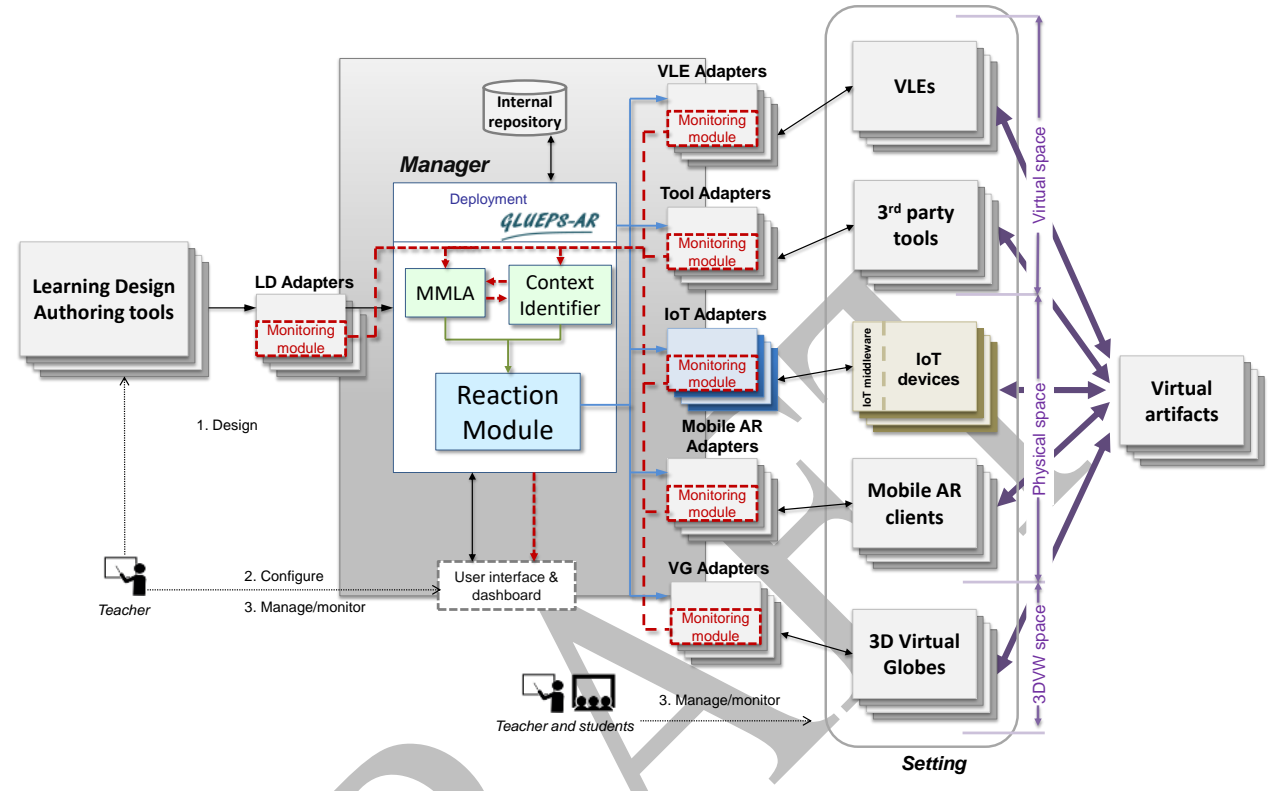

is depicted in grey, while new modules are highlighted with different colors.

\section{Example of a Learning Situation}

For the sake of illustration, a learning scenario supported by the system is presented. During a Natural Science course, the instructor has designed a learning situation aimed at helping students differentiate the trees in the school yard. This situation is composed by three activities: (1) a preliminary quiz, (2) a gymkhana within the school yard where students have to find specific trees in groups and (3) a final report. The system deploys this situation and configures the required resources through the adapters: the quiz and the submit area for the report are created in the VLE, while the IoT beacons placed in the school yard and configured to represent each of the goals in the gymkhana. Furthermore, an application is installed in participants' cellphones to enable the system gathering information like location or level of noise.

As the learning situation progresses, the system gathers data about how students perform in the activities and reacts according to the students' current context. Adaptations can occur in the formal learning (e.g. the analysis module finds that a 
Serrano-Iglesias S., Bote-Lorenzo M.L., Gómez-Sánchez E., Asensio-Pérez J.I., Vega-Gorgojo G. (2019) Towards the Enactment of Learning Situations Connecting Formal and Non-Formal Learning in SLEs. In: Chang M. et al. (eds) Foundations and Trends in Smart Learning. Lecture Notes in Educational Technology. Springer, Singapore (C) 2019 Springer Nature Switzerland AG. Part of Springer Nature. The final authenticated version is available online at https://doi.org/10.1007/978-981-13-6908-7_27

group is struggling in the gymkhana, as they visit random trees without clear intention, and the Reaction Module decides to change their next goal of offer them some clue). But interventions also address the potential of non-formal learning, for example if the context module detects (through the student cellphone) that she is walking through a park. In that case, the reaction module can suggest some extra resource (e.g. a web page with information on the trees of the park) or activity (e.g. a trivia game with questions about trees) that reinforce her learning towards the goals of the formal learning design.

\section{$4 \quad$ Conclusions and Future Work}

SLEs can potentially enhance students' learning connecting formal and non-formal learning, but they need relevant resources for both contexts. The architecture proposed addresses this issue, reacting to students' actions across-spaces. Future pilot scenarios will evaluate the system's interventions and users' impressions.

\section{Acknowledgements}

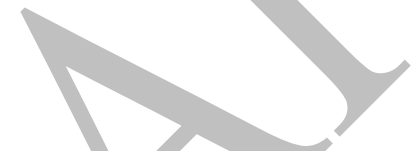

This research has been partially funded by projects TIN2014-53199-C3-2-R (AEI, ERDF), TIN2017-85179-C3-2-R (AEI, ERDF) and 588438-EPP-1-2017-1-ELEPPKA2-KA (European Commission).

\section{References}

[1] Hwang, G.-J.: Definition, framework and research issues of smart learning environments - a context-aware ubiquitous learning perspective. Smart Learning Environments, 1:4, 1-14 (2014)

[2] Delgado Kloos, C., Hernández-Leo, D., Asensio-Pérez, J.I.: Technology for Learning across Physical and Virtual Spaces. J. Univers. Comput. Sci., 18:15, 2093-2096 (2012)

[3] Kinshuk, Chen, N.-S., Cheng, I.-L., Chew, S. W.: Evolution Is not enough: Revolutionizing Current Learning Environments to Smart Learning Environments. International Journal of Artificial Intelligence in Education, 26:2, 561-581 (2016)

[4] Muñoz-Cristobal, J.A., Rodríguez-Triana, M.J., Gallego-Lema, V., Arribas-Cubero, H.F., Asensio-Pérez, J.I., Martínez-Monés, A.: Monitoring for Awareness and Reflection in Ubiquitous Learning Environments. Int. J. Hum-Comput. Int, 32:2, 146-165 (2017)

[5] Blikstein, P.: Multimodal Learning Analytics. In: Proc. of the 3rd International Conference on Learning Analytics and Knowledge (LAK'13), pp. 102-106, Leuven, Belgium (2013) 